\title{
Morphology of the southern African geomagnetic field derived from observatory and repeat station survey observations: 2005-2014
}

\author{
P. B. Kotzé ${ }^{*}$ and M. Korte ${ }^{2}$
}

\begin{abstract}
Geomagnetic field data from four observatories and annual field surveys between 2005 and 2015 provide a detailed description of Earth's magnetic field changes over South Africa, Namibia and Botswana on time scales of less than 1 year. The southern African area is characterized by rapid changes in the secular variation pattern and lies in close proximity to the South Atlantic Anomaly (SAA) where the geomagnetic field intensity is almost $30 \%$ weaker than in other regions at similar latitudes around the globe. Several geomagnetic secular acceleration (SA) pulses (geomagnetic jerks) around 2007, 2010 and 2012 could be identified over the last decade in southern Africa. We present a new regional field model for declination and horizontal and vertical intensity over southern Africa (Southern African REGional (SAREG)) which is based on field survey and observatory data and covering the time interval from 2005 to 2014, i.e. including the period between 2010 and 2013 when no low Earth-orbiting vector field satellite data are available. A comparative evaluation between SAREG and global field models like CHAOS-5, the CHAMP, Orsted and SAC-C model of the Earth's magnetic field and International Geomagnetic Reference Field (IGRF-12) reveals that a simple regional field model based on a relatively dense ground network is able to provide a realistic representation of the geomagnetic field in this area. We particularly note that a global field model like CHAOS-5 does not always indicate similar short-period patterns in the field components as revealed by observatory data, while representing the general secular variation reasonably well during the time interval without near-Earth satellite vector field data. This investigation further shows the inhomogeneous occurrence and distribution of secular variation impulses in the different geomagnetic field components and at different locations in southern African.
\end{abstract}

Keywords: Magnetic observatories, Regional field modelling, Secular variation, Geomagnetic jerks

\section{Introduction}

Geomagnetic secular variation (SV), the change of the magnetic core field, has for a long time been known to proceed in an irregular manner across the globe (Bullard 1948). Southern Africa lies on the brink of the South Atlantic Anomaly (SAA) where the field intensity is up to $30 \%$ weaker than in comparable latitudes, and the secular variation is particularly strong in this region (e.g. Mandea et al. 2007). These strong and inhomogeneous field changes call for frequent updates of regional

\footnotetext{
* Correspondence: pkotze@sansa.org.za

${ }^{1}$ South African National Space Agency (SANSA), Space Science, Hermanus, South Africa

Full list of author information is available at the end of the article
}

field component maps for practical applications and for good secular variation descriptions. Moreover, to better understand the mechanisms underlying the generation of the Earth's magnetic field, it is necessary to obtain long records of field evolution stretching over several decades. In southern Africa, encompassing South Africa, Namibia and Botswana, three geomagnetic observatories provide continuous data series for several decades and repeat surveys have been conducted on a routine basis for nearly 50 years. Since 2005, they have been executed on an annual basis and an additional observatory has been established in southern Namibia (Korte et al. 2009), in order to better monitor the observed rapid geomagnetic field changes in this region (Kotzé et al. 2007; Korte et al. 2007).

\section{实 Springer}

(c) 2016 Kotzé and Korte. Open Access This article is distributed under the terms of the Creative Commons Attribution 4.0 International License (http://creativecommons.org/licenses/by/4.0/), which permits unrestricted use, distribution, and reproduction in any medium, provided you give appropriate credit to the original author(s) and the source, provide a link to the Creative Commons license, and indicate if changes were made. 
Regional magnetic field models are the ideal method to produce field component maps in a timely manner. Different methods to model the geomagnetic field on a regional scale were reviewed by Haines (1990). The southern African ground survey data have been used to derive various regional main field and/or secular variations models, using the methods of polynomials for the time intervals 2004-2005 (Kotzé et al. 2007) and 2005-2009 (Kotzé 2011; Geese et al. 2011), spherical cap harmonic functions for 1975-2000 (Kotzé 2003) and harmonic splines for 1961-2001 (Geese et al. 2010) and 2005-2009 (Geese et al. 2011). Polynomials have also been applied to model the CHAllenging Minisatellite Payload (CHAMP) satellite data of southern Africa (Nahayo and Kotzé 2012). Comparisons of different methods have shown that considering the geomagnetic main field and its secular variation on scales on the order of several $1000 \mathrm{~km}$ low-degree two-dimensional polynomials provide suitable representations of the field components for many applications (Geese et al. 2011). Here, we model main field and secular variation data from the ground station network of the geomagnetic field components declination $(D)$, horizontal intensity $(H)$ and vertical intensity $(Z)$ for the period 2005-2014, using polynomials that can be expressed as a function of latitude and longitude.

Since 2000, global geomagnetic field models are generally well-constrained by satellite magnetic field data with a worldwide denser and more homogeneous data coverage than from ground data alone. However, the end of the CHAMP (http://op.gfz-potsdam.de/champ/) satellite mission in September 2010 left a gap in magnetic vector data coverage from low Earth-orbiting satellites until the launch of the ESA Swarm constellation (http://www.esa.int/ Our_Activities/Observing_the_Earth/The_Living_Planet_ Programme/Earth_Explorers/Swarm/ESA_s_magnetic field_mission_Swarm) in November 2013. The CHAOS-5 model (Finlay et al. 2015) is one of the first geomagnetic field models spanning that gap. It is based on satellite observations (Ørsted, CHAMP, SAC-C and SWARM A, $B$ and $C)$ as well as observatory monthly mean data. The internal part of CHAOS-5 is time-dependent up to degree and order 20 and involves sixth-order splines with a 0.5 -year spacing to provide secular variation information between 1999 and 2015 as well as secular variation predictions from 2015 till 2020. This global model is used for cross-validation with our new regional model.

Sudden changes of secular variation trends are known as geomagnetic jerks (see Mandea et al., 2010 for a review). In geomagnetic field component time series, they appear as sharp changes of slope, often maxima or minima, of secular variation, the first derivative of the field, and are characterized by pulses or 'jumps' in secular acceleration (SA), the second time derivative. However, no clear definition for geomagnetic jerks exists. Following the detection of some rapid changes occurring regionally over only a few months in magnetic satellite data (Mandea and Olsen 2006; Olsen and Mandea 2008), Mandea and Olsen (2009) suggested to distinguish between jerks and rapid secular variation fluctuations. This distinction refers to underlying mechanisms in the core fluid flow, and a clear distinction of features observed in individual data series is not straightforward. Brown et al. (2013) recently showed that regional geomagnetic jerks of varying amplitude have occurred much more frequently over the past decades than previously thought, as only the ones of greatest magnitude and isolation in time have been reported before. For the African region, two geomagnetic jerks have been reported previously for the times since 2005: in 2007 (Chulliat et al. 2010; Kotzé 2010, 2011) and 2011 (Chulliat and Maus 2014). The latter authors ascribe them to two power pulses in secular acceleration that occurred at the core-mantle boundary (CMB) in 2006 and 2009. Another SA pulse at the CMB was reported recently by Chulliat et al. (2015) to have occurred in 2012.5, based on results from magnetic satellite data and global models. Torta et al. (2015) report on surface observations of this jerk around 2014. We investigate the occurrence and morphology of these and further rapid SV variations in southern Africa between 2005 and 2014 using ground data.

In the following sections, we first describe the used data and modelling method and apply it to obtain the Southern African REGional (SAREG) model describing both the main field and its secular variation. We analyse the fit to the data in comparison to two global models and describe observed changes in regional secular variation patterns and in time series at the four well-distributed observatory locations, particularly focussing on geomagnetic jerks and rapid secular variation fluctuations.

\section{Geomagnetic observatory and repeat station data}

Continuous recordings of geomagnetic field variations are conducted at the geomagnetic observatories Hermanus (HER), Hartebeesthoek (HBK) and Tsumeb (TSU) since many decades and at Keetmanshoop (KMH) since 2006. All these magnetic observatories comply with INTERMAGNET standards (www.intermagnet.org). Their location is shown in Fig. 1 together with the current southern African geomagnetic survey network consisting of 40 repeat stations with an average spatial separation of $300-400 \mathrm{~km}$. All the repeat stations are marked by concrete beacons, ensuring that all observation points are exactly reoccupied during surveys. Vector field observations at each station are in general done in the evening and morning, with a three-component fluxgate variometer operating the whole time and during the night. Corrections for diurnal and other short-term external field variations are then made by reducing field station observations to nighttime average values (see Korte et al. 2007 for details). 


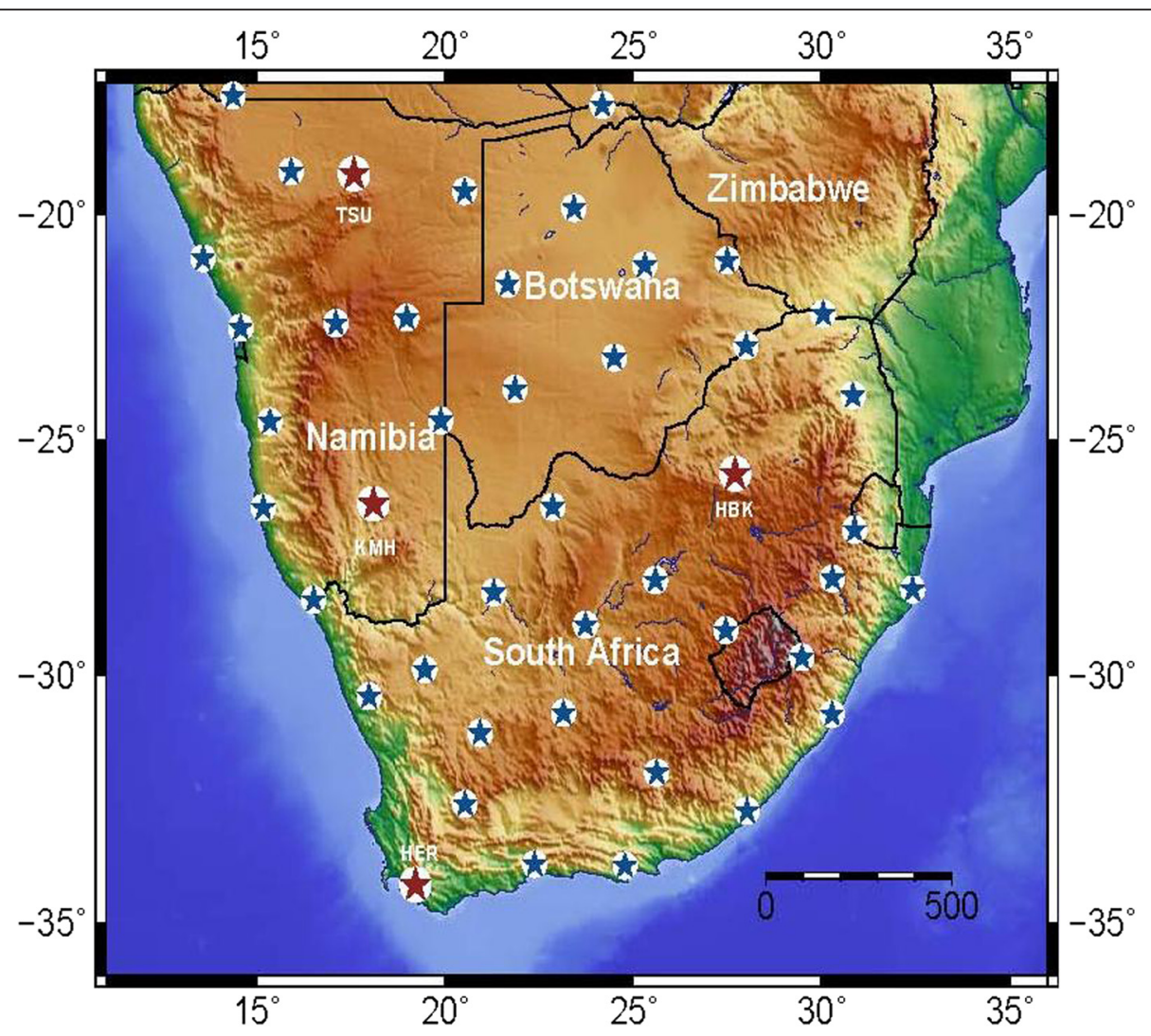

Fig. 1 A map of southern Africa showing the positions of the four INTERMAGNET observatories, HER, HBK, KMH and TSU (red stars), as well as the positions of the repeat stations (blue stars)

This methodology proved to be a vast improvement to the use of only magnetic observatories, sometimes a distance of several hundred kilometres away. Three data sets were considered in this study: observatory and repeat station annual data to obtain (i) main field and (ii) secular variation models for each epoch and denser observatory secular variation time series (iii) for a more detailed analysis of rapid secular variation changes.

(i) Annual main field data: The repeat station measurements were obtained between the middle of September and middle of December each year. As secular variation is small compared to the strength of the main field, we neglect it in this case and consider all repeat station night-time results as representative of the main field at each epoch. This repeat station data set was augmented by standard observatory annual means, averaged over all hours of a year and centred on the middle of a year (year.5).

(ii) Annual secular variation data: Annual secular variation values for the repeat stations were obtained as first differences between consecutive main field data divided by the time interval in years. Individual stations in general were visited at about the same time of the month each year. Therefore, the first differences even eliminate large parts of annual external field variations. Moreover, these first differences also eliminate any constant lithospheric field biases at the stations. Annual secular variation at the observatories was obtained by first differences of standard annual mean values in this case. There are 120 vector differences from 40 repeat stations and 9 vector differences from the 3 observatories, providing a total of 129 data values for a particular time interval. When all 4 observatories were operational, this changed to 132 data values for a particular epoch.

(iii) Observatory secular variation time series: Quiet-time monthly mean values (Kotzé et al. 2015) were used for this purpose. The quiet-time data were selected complying with $K$-indices less than 4 in order to eliminate disturbed and noisy conditions. This selection restriction provided the best compromise between truly quiet times and the amount of data left to derive mean monthly values. In order to determine secular variation free from annual variations from magnetospheric and ionospheric currents, including the resulting induction effects, first 
differences of the $D, H$ and $Z$ monthly means at time $t$ were calculated as the difference between those at time $t+6$ months and $t-6$ months. At $\mathrm{KMH}$, reliable absolute data only became available during the second half of 2006. Data from the TSU observatory for 2009 are missing due to unreliable electricity supply to the recording instruments.

Although data uncertainty estimates would be useful for consideration in the modelling, it is not possible to give stringent values for that purpose for any of our data sets. Error estimates for observatory values for $H$ and $Z$ components vary from $1 \mathrm{nT}$ at HER to $1.5 \mathrm{nT}$ for a remote location such as TSU or KMH, depending on the accuracy of the baselines. Similar for $D$, the errors can vary from $10^{\prime \prime}$ at HER to 20 " at places like TSU and $\mathrm{KMH}$. For the repeat stations, an estimate of measurement uncertainties can be obtained from the scatter of the individual results at a particular location and from any observed systematic difference between evening and morning observations. This provides error estimates of $1-2 \mathrm{nT}$ in $H$ and $Z$ and $0.3-0.5 \mathrm{~min}$ in $D$. However, it is not possible to assess how much external field influence remains in any observatory data average or particular night-time value. These contributions, which will often dominate over the measurement uncertainties, should also not be considered by a main field model. We therefore expect any model misfits to be clearly larger than the numbers stated above.

\section{New southern African regional geomagnetic field models}

\section{Polynomial modelling}

We chose polynomials to model the southern African field and secular variation as such models have a simple form, have well-known and understood properties and have moderate flexibility of shapes and are computationally easy to use. However, polynomial models also have limitations such as weak interpolation and extrapolation properties. Polynomials may provide good fits within the range of data, but like most interpolation functions, they deteriorate rapidly outside the range of the data.

We selected a two-dimensional polynomial presentation (Xu et al. 1992):

$$
B(\theta, \gamma)=\sum_{n=0}^{N} \sum_{m=0^{a} n m}^{M}(\theta-\bar{\theta})^{n}(\gamma-\bar{\gamma})^{m}
$$

where $B(\theta, \gamma)$ is the magnitude of each main field component $(D, H$ and $Z)$ of the geomagnetic field at the point with geographic coordinates $\theta$ and $\gamma, a_{n m}$ is a numerical coefficient and $\bar{\theta}$ and $\bar{\gamma}$ are the coordinates of the centre of the modelled area: $\bar{\theta}=26^{\circ} \mathrm{S}$ and $\bar{\gamma}=24^{\circ} \mathrm{E}$. The degree of the two-dimensional polynomial is determined by the values of $N$ and $M(N=M=0,1,2,3 \ldots)$. One of the characteristics of the surface polynomial is that the $a_{n m}$ coefficients for high degrees of $N$ and $M$ converge to zero. However, high-degree polynomials show strong edge effects, effectively reducing the region of validity of the modelled area (Ardizone and Herraiz 2000). Moreover, we aim to model the comparatively large-scale geomagnetic main field and its secular variation, as filtered by the mantle at the Earth's surface. In order to suppress smallerscale lithospheric anomalies in the main field data and local influences from residual external fields or measurement uncertainties, we choose low truncation degrees of $N=M=3$ for the main field (cubic polynomial) and $N=M=2$ (quadratic polynomial) for secular variation.

Several methods exist to determine the statistical significance of model coefficients, e.g. the bootstrap method by Pavón-Carrasco et al. (2014), but in this investigation, a least-squares routine was employed to fit the data in a stepwise regression procedure described by Efroymson (1960) that has the ability of both entering and removing variables at given levels of statistical significance.

\section{Main field components}

The $D, H$ and $Z$ field annual main field data of 2005-2014 described above were used as input data to derive a polynomial main geomagnetic field model of degree 3 for southern Africa at each year. Our data set described above contains observatory and repeat station data. As observatory data, in general, are more accurate than repeat survey data (because of better baseline control and because seasonal and other short-term variations are more effectively removed by using annual means), we weighted observatory and repeat station secular variation data in a ratio 1:0.7 in the least-squares solution. In order to model primarily the core field at each epoch, a maximum number of 10 statistically significant coefficients were used, corresponding to a minimum wavelength of approximately $2200 \mathrm{~km}$. These model parameters ensure that predominantly only core field contributions be modelled and that edge effects at the boundaries could be largely eliminated. Although care has been taken to minimize external field effects during field surveys, the models do, however, contain a small amount of large-scale magnetospheric, mostly ring current, contributions (Korte 2015). As these large-scale fields varying on time scales of the core field are inevitably included in any field observations including those for navigational or prospecting purposes, it is reasonable to keep them in main field models for practical applications. The RMS (root-mean-square) differences between model and observations can be seen in Table 1 . Note that these values clearly are dominated by lithospheric field bias at the data locations. 
Table 1 RMS differences between field survey $D$ (min), $H$ (nT) and $Z(\mathrm{nT})$ main field components and different geomagnetic field models over the southern African region from 2005 till 2014

\begin{tabular}{|c|c|c|c|c|c|c|c|c|c|}
\hline \multicolumn{10}{|c|}{ RMS differences: main field (obs) model } \\
\hline \multirow[t]{2}{*}{ Year } & \multicolumn{3}{|c|}{ SAREG model } & \multicolumn{3}{|c|}{ IGRF-12 } & \multicolumn{3}{|c|}{ CHAOS-5 } \\
\hline & D & $H$ & Z & $D$ & $H$ & Z & $D$ & $H$ & Z \\
\hline 2005 & 28.0 & 63.9 & 155.6 & 32.5 & 81.4 & 178.6 & 32.6 & 79.6 & 179.2 \\
\hline 2006 & 27.0 & 63.1 & 153.0 & 32.3 & 75.8 & 172.6 & 31.2 & 74.9 & 173.8 \\
\hline 2007 & 28.1 & 66.8 & 153.5 & 32.0 & 78.1 & 173.0 & 30.9 & 76.9 & 173.8 \\
\hline 2008 & 27.2 & 65.4 & 148.1 & 31.4 & 78.0 & 168.9 & 30.7 & 75.9 & 168.3 \\
\hline 2009 & 27.8 & 62.6 & 123.5 & 31.3 & 79.3 & 160.0 & 31.1 & 76.1 & 158.8 \\
\hline 2010 & 29.6 & 66.9 & 142.3 & 32.9 & 80.0 & 159.6 & 33.1 & 77.2 & 159.6 \\
\hline 2011 & 29.3 & 66.1 & 135.5 & 33.6 & 80.6 & 168.9 & 34.1 & 79.6 & 169.0 \\
\hline 2012 & 23.3 & 62.7 & 128.4 & 27.0 & 71.5 & 158.6 & 27.4 & 70.0 & 159.5 \\
\hline 2013 & 25.8 & 59.1 & 127.3 & 27.7 & 82.4 & 145.8 & 28.1 & 79.3 & 147.2 \\
\hline 2014 & 27.5 & 63.1 & 160.1 & 30.6 & 75.1 & 175.1 & 31.1 & 73.0 & 175.5 \\
\hline
\end{tabular}

\section{Secular variation observations}

Since secular variation is not measured directly, but is derived as a time derivative of the geomagnetic field, one can model the main field and then differentiate the corresponding field model to get a secular variation model, or one can numerically differentiate the main field data and then fit a secular variation model directly by replacing $B$ by $\mathrm{d} B / \mathrm{d} t$ in Eq. 1 . The latter derivative-fit approach is able to remove crustal contamination which is the overwhelming source of error in determining a main field model (Cain et al. 1965; Dawson and Newitt 1978). Observatory and repeat station data are weighted in a ratio of 1:0.7 in the final least-squares solution in order to take into account the higher accuracy of observatory data. This ratio was determined by minimizing the RMS difference between model fits and survey data. Annual secular variation models for the periods 2005.5-2006.5 (2006) to 2013.5-2014.5 (2013) were subsequently derived. Each secular variation model consists of six statistically significant coefficients for each magnetic field component modelled. The scatter about the fit for declination secular variation was $1.5 \mathrm{~min} / \mathrm{year}$, while for $H$ and $Z$ secular variation, it was 5.1 and $4.8 \mathrm{nT} /$ year, respectively (Table 2). The misfit in this case includes measurement uncertainties and external field residuals.

The main field and secular variation models collectively form a regional geomagnetic field model for southern Africa, including countries such as South Africa, Namibia and Botswana, called SAREG. Although SAREG consists of individual models with model coefficients at 1-year intervals, cubic B-spline interpolation of the timedependant secular variation coefficients between 2005 and 2014 provides a continuous transition between different epochs.
Table 2 RMS differences between field survey $D$ (min/year), $H$ (nT/year) and Z (nT/year) secular variation components and different geomagnetic field models over the southern African region from 2006 till 2014

\begin{tabular}{|c|c|c|c|c|c|c|c|c|c|}
\hline \multicolumn{10}{|c|}{ RMS differences: secular variation (obs) model } \\
\hline \multirow[t]{2}{*}{ Year } & \multicolumn{3}{|c|}{ SAREG model } & \multicolumn{3}{|c|}{ IGRF-12 } & \multicolumn{3}{|c|}{ CHAOS-5 } \\
\hline & $D$ & $H$ & Z & $D$ & $H$ & Z & $D$ & $H$ & Z \\
\hline $2005-2006$ & 1.12 & 2.92 & 2.33 & 1.55 & 5.47 & 3.43 & 1.30 & 5.70 & 4.40 \\
\hline 2006-2007 & 1.98 & 4.96 & 3.86 & 1.84 & 4.86 & 4.05 & 1.74 & 4.17 & 3.93 \\
\hline 2007-2008 & 1.71 & 4.20 & 4.78 & 2.32 & 5.04 & 4.86 & 1.50 & 5.05 & 5.08 \\
\hline 2008-2009 & 1.50 & 2.84 & 4.01 & 1.37 & 4.02 & 5.23 & 1.15 & 3.17 & 4.59 \\
\hline 2009-2010 & 2.05 & 3.41 & 4.10 & 1.61 & 3.63 & 4.58 & 1.41 & 4.62 & 4.09 \\
\hline 2010-2011 & 1.31 & 3.58 & 4.54 & 1.36 & 3.68 & 4.06 & 1.22 & 3.68 & 4.51 \\
\hline 2011-2012 & 1.31 & 4.26 & 3.89 & 0.89 & 5.92 & 4.14 & 1.01 & 4.64 & 3.60 \\
\hline 2012-2013 & 0.98 & 4.17 & 2.34 & 1.05 & 4.80 & 2.63 & 1.11 & 4.79 & 2.83 \\
\hline 2013-2014 & 1.07 & 3.97 & 2.70 & 1.04 & 5.04 & 2.99 & 1.22 & 5.65 & 3.91 \\
\hline
\end{tabular}

\section{Results and model comparisons}

\section{SAREG regional field component maps}

The polynomial SAREG geomagnetic field model for each annual field survey from 2005 till 2014 not only describes main field components but also the time variation between surveys. A comparative evaluation between each model and both the International Geomagnetic Reference Field, IGRF-12 (Thébault et al. 2015), and CHAOS-5 spherical harmonic global field models revealed almost similar RMS (root-mean-square) differences between observations and model values as shown in Tables 1 and 2 for main field and secular variation, respectively.

This also shows that the regional polynomial models provide statistically significantly slightly better fits to the field observations in comparison to the two global field models used in this investigation as can be expected from the regional modelling of geomagnetic field components. Like the two global spherical harmonic models, the SAREG regional model only represents core field characteristics with very little crustal field effects but might contain more of the weak long-term magnetospheric field contributions. The SAREG model was subsequently used to calculated values for $D, H$ and $Z$ at $0.5^{\circ}$ intervals for the area between $25^{\circ} \mathrm{S}$ and $35^{\circ} \mathrm{S}$ and between $12^{\circ} \mathrm{E}$ and $32^{\circ} \mathrm{E}$ at each epoch. Typical examples of contour plots for $D, H$ and $Z$ for 2014.5 are shown in Fig. 2a-c, respectively. Similar results have been obtained at all other epochs. Noticeable is the huge gradient in $D$ over southern Africa, ranging from $28^{\circ} \mathrm{W}$ in the southern part to $8^{\circ} \mathrm{W}$ in the northern part of the region.

The secular variation polynomial models were subsequently used to calculate annual variation values for $D$, $H$ and $Z$ at $0.5^{\circ}$ intervals for the same region at each epoch from 2006 till 2014 and are shown in Figs. 3, 4 

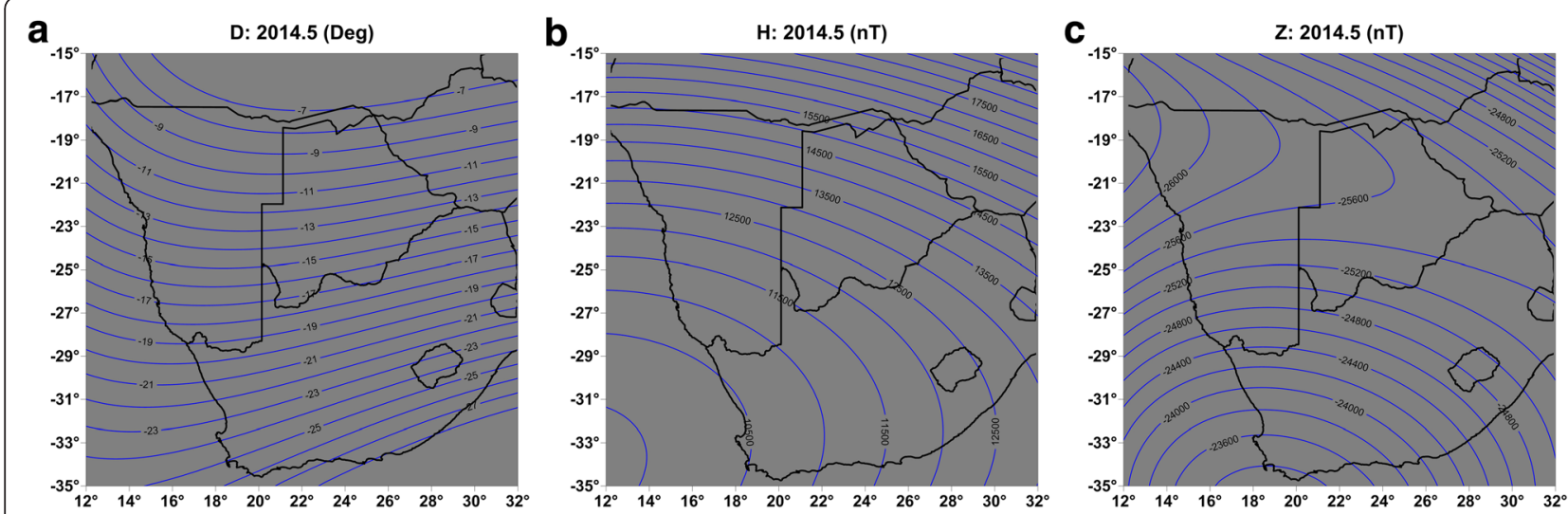

Fig. 2 Contour plots of the geomagnetic field 2014.5 over southern Africa as determined by the SAREG polynomial model. For declination, a the contour interval is $1^{\circ}$, while all values indicate West of geographic North. For horizontal intensity, $\mathbf{b}$ the contour interval is $500 \mathrm{nT}$, and for vertical intensity, c contour interval is $200 \mathrm{nT}$

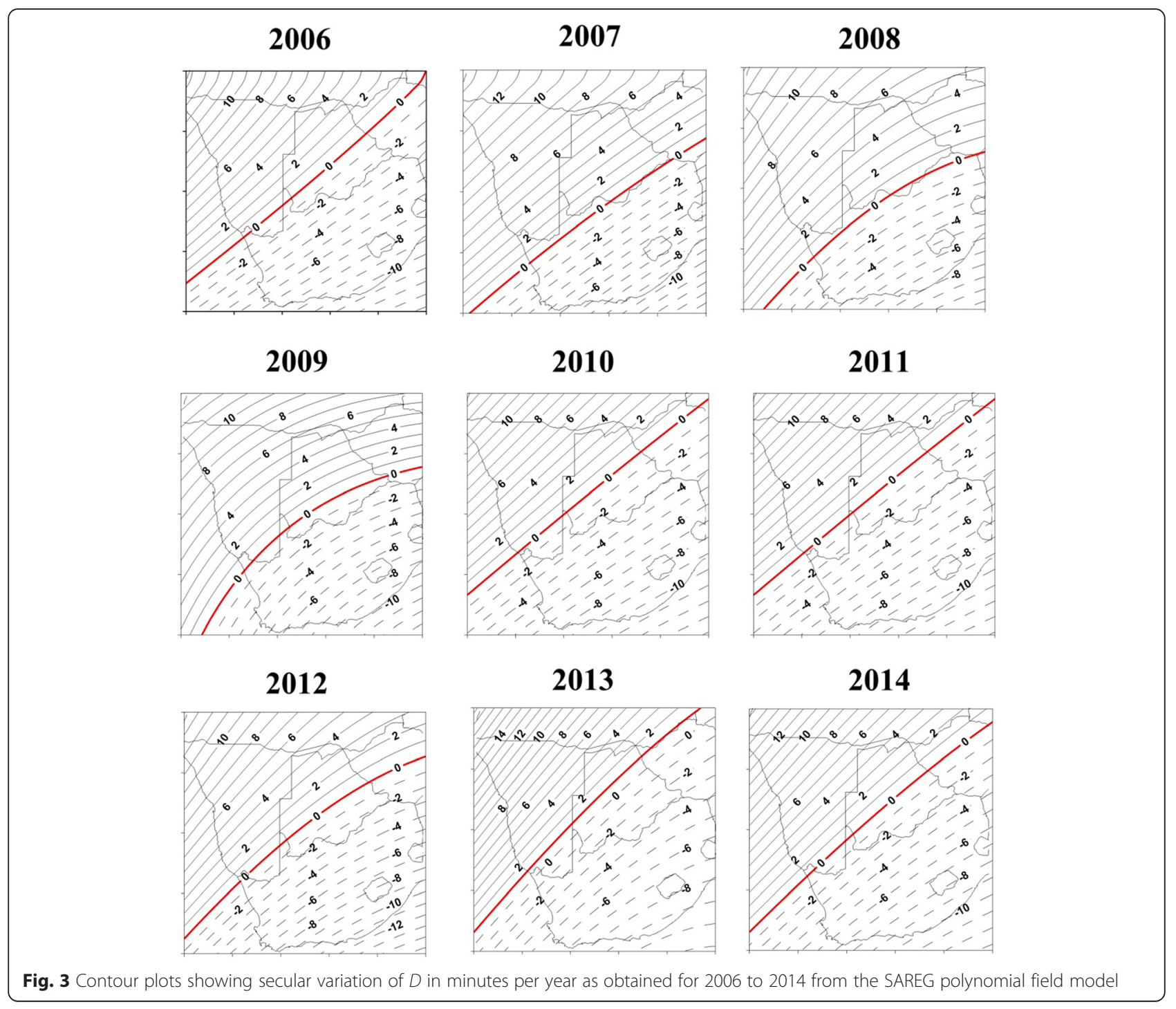


2006

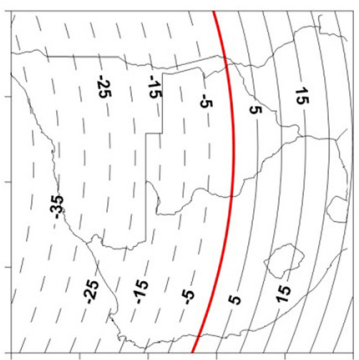

2009

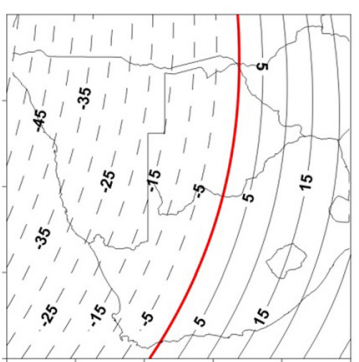

2012

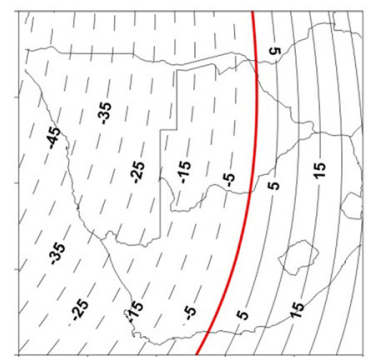

2007

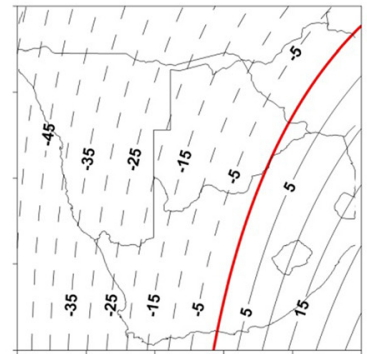

2010

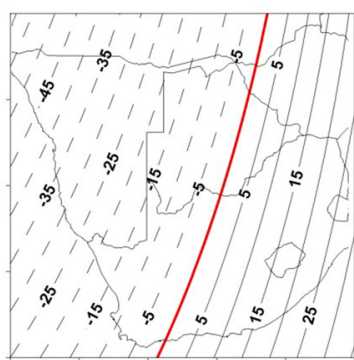

2013

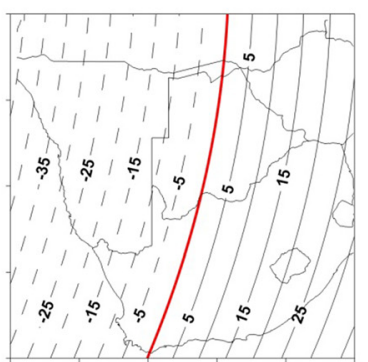

2008

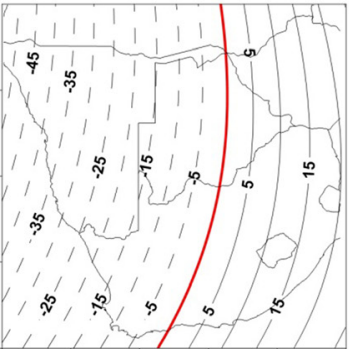

2011

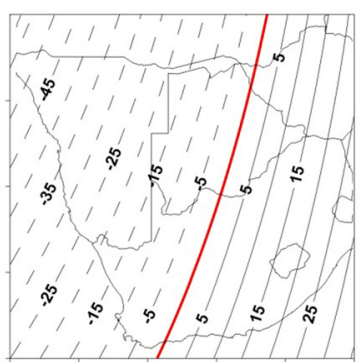

2014

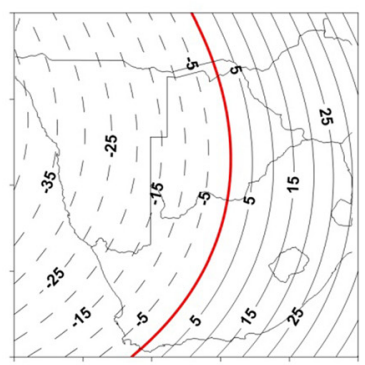

Fig. 4 Contour plots showing secular variation of $H$ in nanotesla per year from 2006 to 2014 as obtained from the SAREG polynomial field model

and 5 with red contours representing lines of zero secular variation. The declination secular variation (Fig. 3) pattern, and in particular the zero contour line, shows alternating south-west and north-east movements during this period. Three distinct changes of contour line directional movement, particularly during 2007, 2010 and 2013, are direct evidence of geomagnetic jerks that occurred in the region. The 2007 one (Kotzé 2010, 2011) is best observed, and the regional model reveals the inhomogeneity of the jerk: it starts around 2007.5 in the centre of the study area and occurs slightly later but with higher amplitudes in the south-western and northeastern parts of the region. The 2010.5 jerk, on the other hand, appears quite homogeneous over the study area, while the weak 2013 one has higher amplitude in the north-east (Botswana) than the rest of the region.
The secular variation behaviour of the horizontal component $(H)$ from 2006 till 2014 can be seen in Fig. 4. This component also displays a slightly variable dichotomy of secular variation over the study area with negative values in the west and positive ones in the east. Here, a change from increasing SV (contour lines moving east) to decreasing SV (contour lines moving west) occurs slightly earlier than in declination, at some time between 2007 and 2008. The last 2 years of the model shows an alternation of rather rapid horizontal component SV increase (2012 to 2013) then a decrease (2013 to 2014) in the centre of the area, while the northern and southern parts are characterized by continuing increase.

In the case of $Z$ (Fig. 5), the secular variation is positive across almost the whole of southern Africa. Positive secular variation values in this case indicate a decrease 


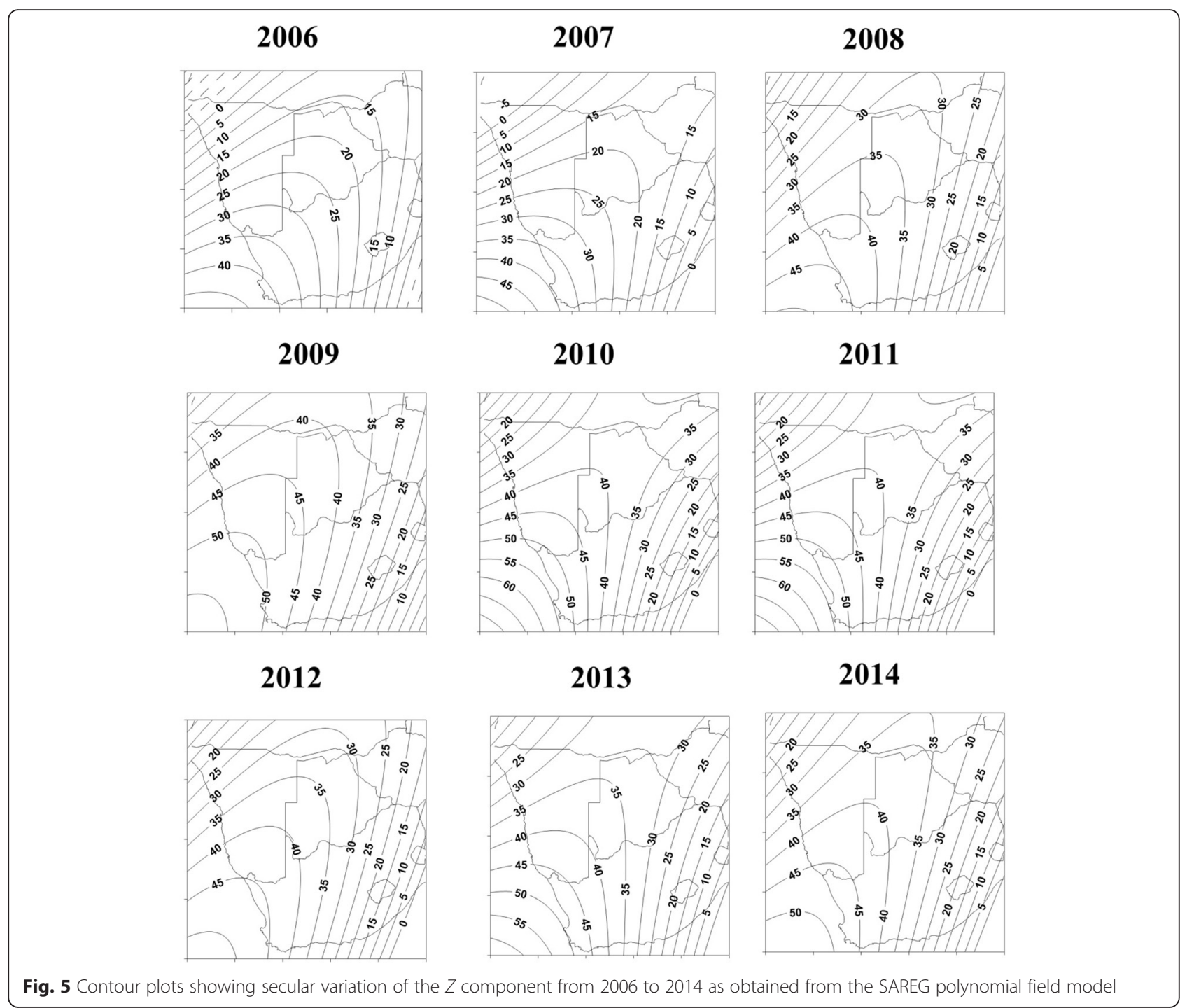

of absolute vertical field intensity, as that component is negative in the Southern Hemisphere. A change of trend takes place around 2007.5, followed by another change in SV rate between 2009 and 2010. The following $Z$ component SV change occurs over the northern parts of the study region around 2013.5. The comparison of the three components confirms strong and inhomogeneous SV activity in southern Africa. Abrupt changes in SV mostly occur at different times in the individual components.

\section{Secular variation at the observatory locations}

In order to better characterize the times of the rapid secular variation changes and compare how well the regional and a global model describe the secular variation in the southern African region, we investigate the component time series at the four observatory locations. Secular variation of $D$ (min/year), $H$ (nT/year) and $Z$
(nT/year) components at HER, HBK, KMH and TSU are shown in Figs. 6, 7, 8 and 9, respectively, as a function of time between 2005.5 and 2014.0 as determined by running annual differences of the quiet-time monthly mean values. In the case of $\mathrm{KMH}$, the time interval stretches between 2007 and 2013 due to the availability of reliable data. Predictions of secular variation from the SAREG secular variation model interpolated by cubic B-splines and from the global CHAOS-5 model are included in these plots.

Additionally, rates of SV were estimated directly from the time series by piecewise linear fits, which are also shown in Figs. 6, 7, 8 and 9. To determine the break points between two linear segments, an algorithm searched for a distinctive change in the slope of consecutive segments. An iterative method was then followed to obtain the best linear fit and subsequently the slope of a particular time interval by optimizing the regression coefficient. In 

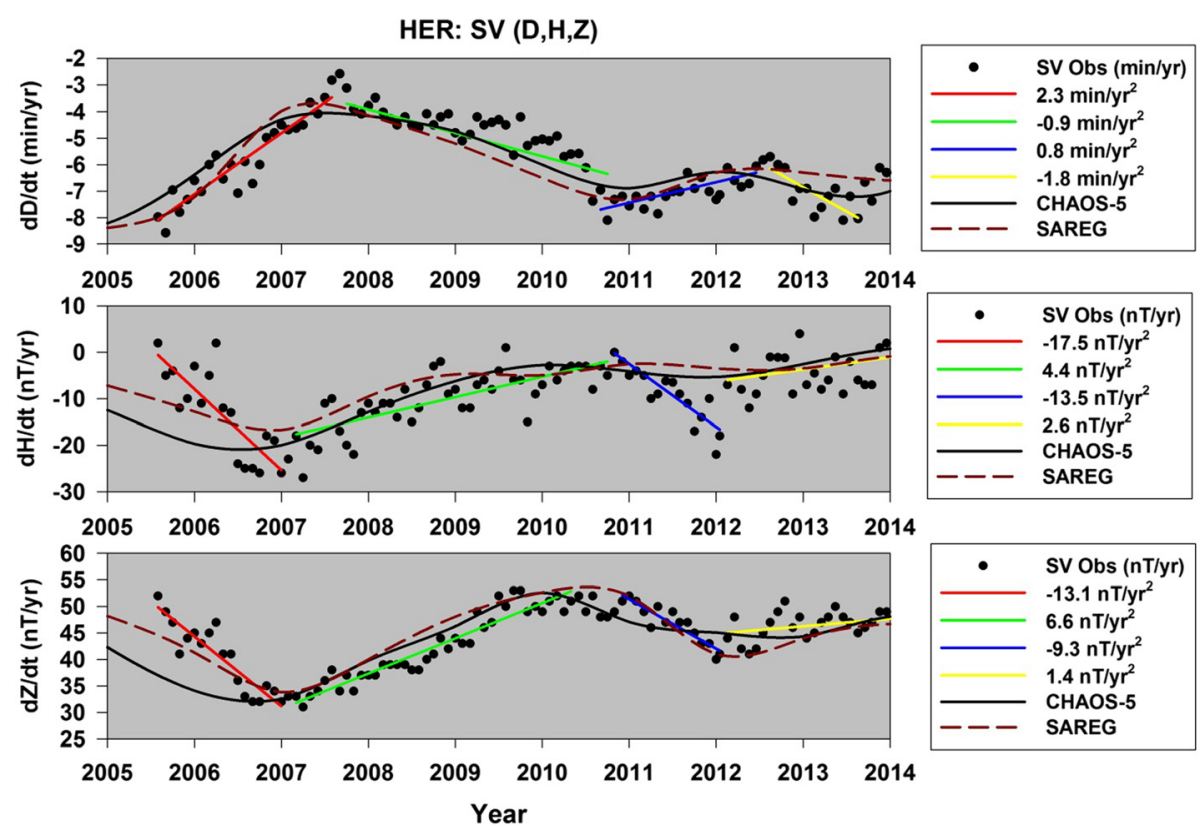

Fig. 6 Secular variation of $D, H$, and $Z$ components at Hermanus observatory as derived from monthly mean measurements between 2005 and 2014. The black dots show monthly mean secular variation estimates used as running annual differences. The CHAOS-5 global field model (black line) and the SAREG regional model (brown dashed line) are included. Piecewise linear fits to the data provide estimates of secular acceleration as given in the legends

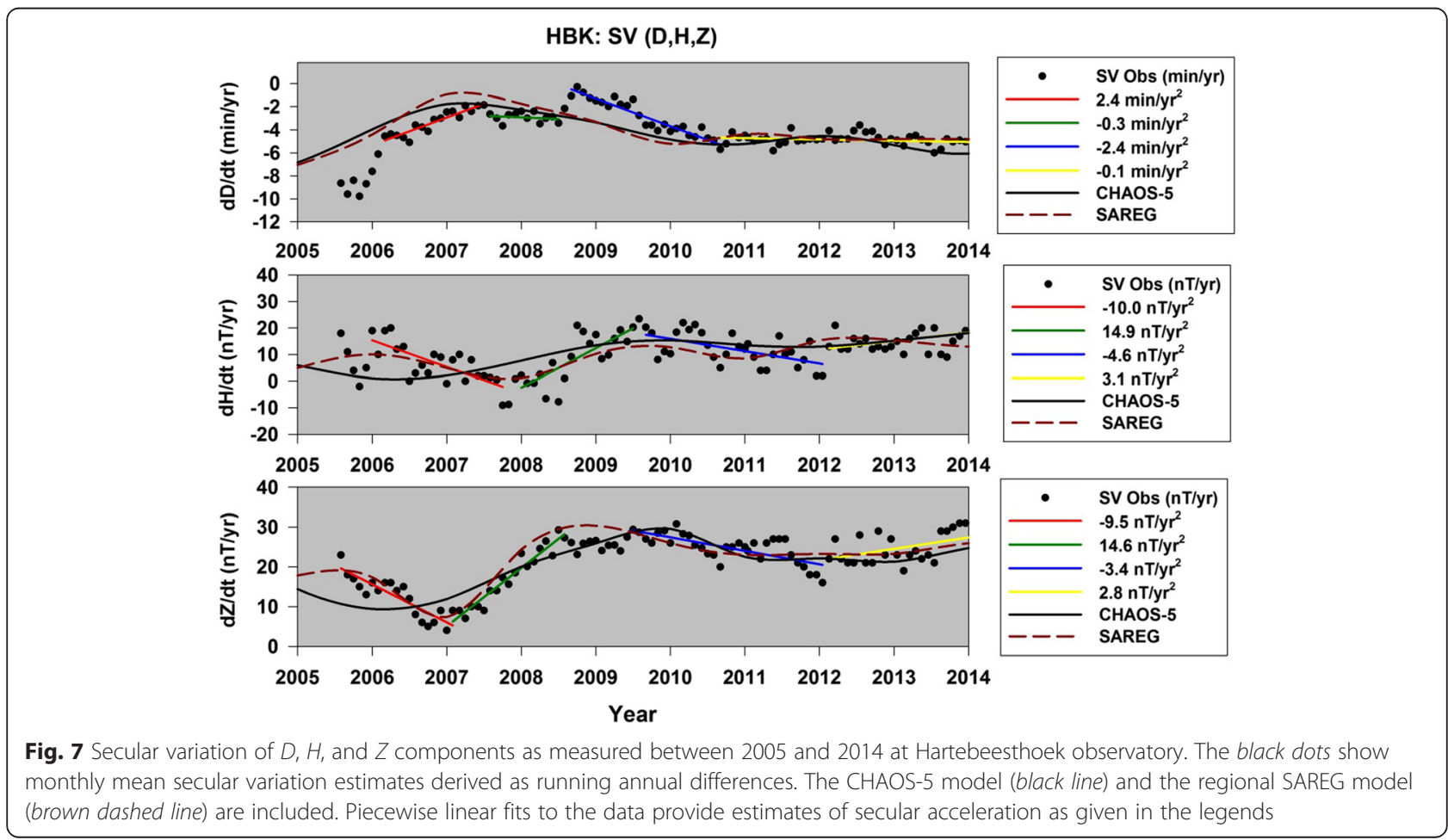




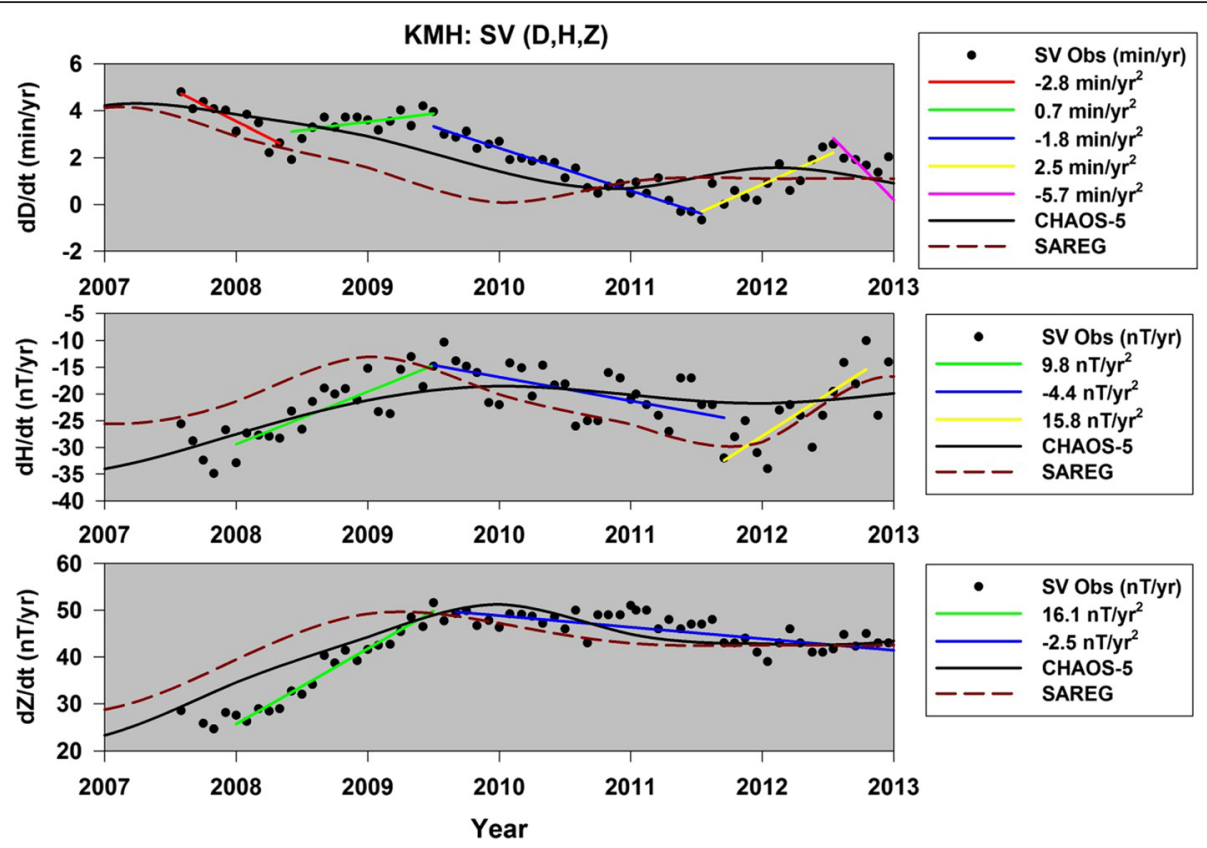

Fig. 8 Secular variation of $D, H$, and Z components at Keetmanshoop observatory between 2007 and 2013. The black dots show monthly mean secular variation estimates derived as running annual differences. Both the CHAOS-5 (black line) and SAREG (brown dashed line) models are included. Piecewise linear fits to the data provide estimates of secular acceleration as given in the legends

some instances, this led to a gap of several months between two linear fits, e.g. in the case of $\mathrm{Z}$ at HBK when the secular variation stayed constant for several months around 2009. The strengths of rapid SV changes or jerks are listed in Table 3.
The HER time series from the south of the studied area clearly reflects all the rapid fluctuations noted in the regional maps and all components but indicates that the changes of secular variation rates occur more rapidly than described by either of the models. In $D$, secular

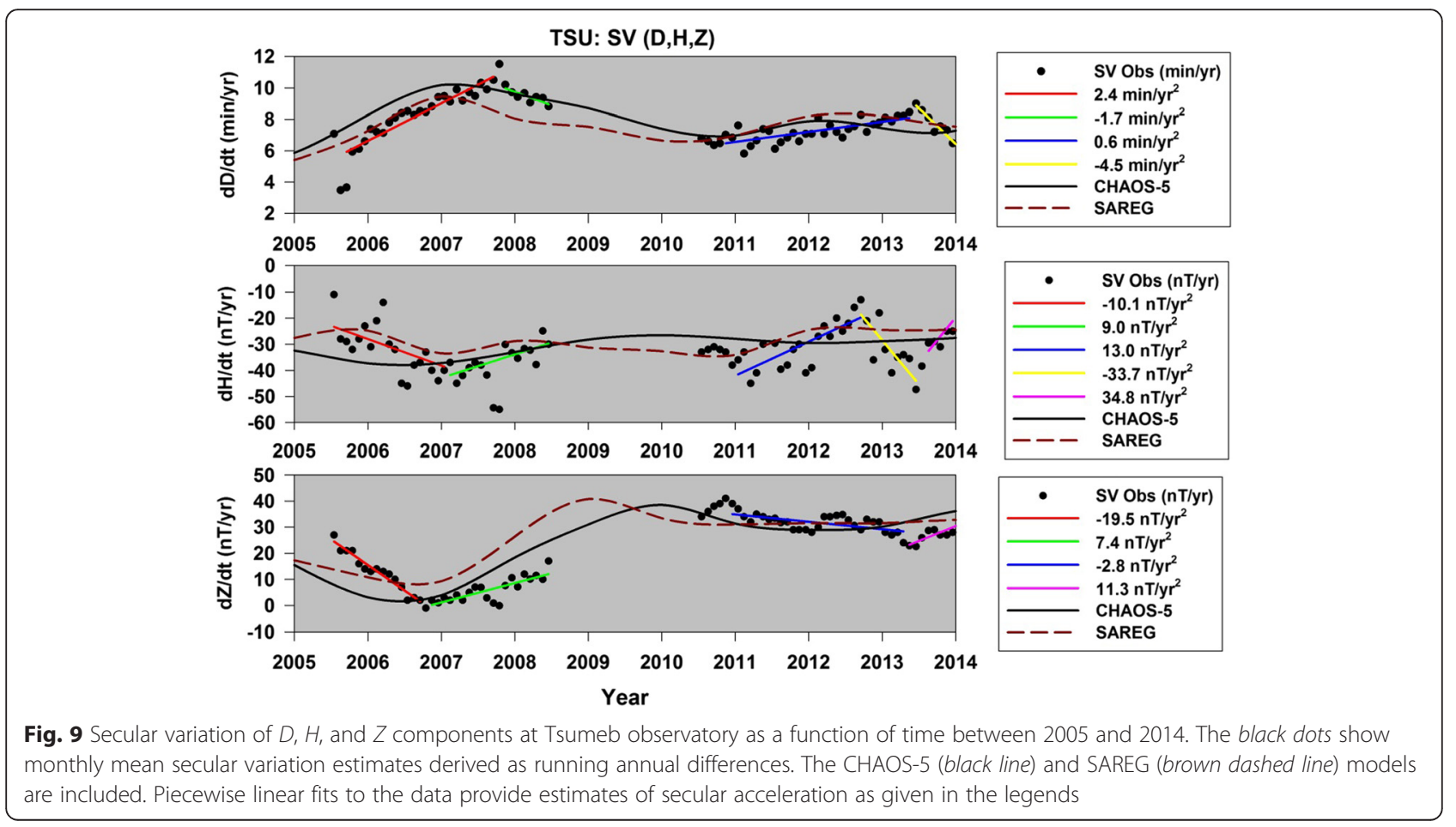


Table 3 Amplitudes and signs of secular acceleration changes at the four observatories as determined from changes of slope of the piecewise linear fits (Figs. 6, 7, 8 and 9)

\begin{tabular}{|c|c|c|c|c|}
\hline Interval & HER & HBK & $\mathrm{KMH}$ & TSU \\
\hline \multicolumn{5}{|c|}{ Declination (min/year ${ }^{2}$ ) } \\
\hline 2007-2008 & -3.2 & -2.7 & No data & -4.1 \\
\hline 2008-2009 & - & -2.1 & 3.5 & No data \\
\hline 2009-2010 & - & - & -2.5 & No data \\
\hline 2010-2011 & 1.7 & 2.3 & - & No data \\
\hline 2011-2012 & - & - & 4.3 & - \\
\hline 2012-2013 & -2.6 & - & -8.2 & - \\
\hline 2013-2014 & Insufficient data & - & No data & -5.1 \\
\hline \multicolumn{5}{|c|}{ Horizontal intensity (nT/year²) } \\
\hline 2007-2008 & 21.9 & 24.9 & No data & 19.1 \\
\hline 2008-2009 & - & - & - & No data \\
\hline 2009-2010 & - & -19.5 & -14.2 & No data \\
\hline 2010-2011 & -17.9 & - & - & No data \\
\hline $2011-2012$ & - & - & 20.2 & - \\
\hline 2012-2013 & 16.1 & 7.7 & - & -46.7 \\
\hline 2013-2014 & - & - & No data & 68.5 \\
\hline \multicolumn{5}{|c|}{ Vertical intensity (nT/year ${ }^{2}$ ) } \\
\hline 2007-2008 & 19.7 & 16.1 & No data & 26.9 \\
\hline 2008-2009 & - & -18.0 & - & No data \\
\hline 2009-2010 & - & - & -18.6 & No data \\
\hline 2010-2011 & -15.9 & - & - & No data \\
\hline $2011-2012$ & - & - & - & - \\
\hline 2012-2013 & 10.7 & 6.2 & - & - \\
\hline 2013-2014 & - & - & No data & 14.1 \\
\hline
\end{tabular}

variation varies between -8 and $-2.6 \mathrm{~min} /$ year with three rapid changes in 2007.5, 2010.5 and 2012.5. Another SA pulse seems to have occurred in 2013.5, but the length of the time series does not allow a robust estimation of SA for the most recent times. The strongest SV occurred from the beginning of the studied time interval to 2007.5 with $2.3 \mathrm{~min} /$ year. Horizontal and vertical components at this location show very similar occurrences of SV changes with a rapid change in 2007.0, slightly earlier than in $D$, and another abrupt change at about 2012.0, again about half a year earlier than in $D$.

At HBK in the eastern part of the studied area, the rapid SV changes detected in the regional maps are not so clearly seen in all components, and $H$ and $Z$ components show less similar variations than in HER in the south. In $D$, a change of SV rate in 2007.5 is not very pronounced but followed by another change about a year later. The change in 2010.5 is visible but also weaker than at HER, and no further rapid changes show up in this component. In $H$, the first rapid change with comparable amplitude as seen at HER occurs several months later than there, coinciding closer with the declination jerk in the second half of 2007. A change of SV trend from positive to negative rates in 2009.5 is on the other hand more pronounced here than at HER. The third rapid change in this component is seen at the same time, around 2012.0, but with only about half the amplitude compared to HER. The clear jerk of 2007.0 in the $Z$ component is of comparable amplitude as HER here. A change from positive to negative vertical component SA with nearly constant SV over about a year occurs about 1.5 years earlier here than in the south, while a coeval change of low amplitude is seen at 2012.0.

At KHM, in the western central part of the studied area, good quality continuous data are only available from 2007 on, and an apparent 'jump' in SV in all three components at 2013.0 might be an artefact caused by baseline problems due to a defective absolute instrument. The time series thus does not allow the identification of the 2007 jerk, and we refrain from interpreting SV changes after 2012.5 at this location. Interestingly, here, we see coinciding SV changes in all three components around 2009.5. For $D$, this is a rather different field behaviour than at the other locations. The second rapid change observed in this component, around 2011.5, occurs about a year later than at HER and HBK to the south and east, respectively. The 2009.5 change in $H$ coincides with the one seen at HBK and is of similar amplitude, and another one around 2012.0 seems to have occurred a few months earlier than at HER and HBK and with larger amplitude. The $Z$ component at this location only shows one distinct change of SV trend with similar amplitude as further south and east and a few months of nearly constant SV.

At TSU, our northernmost location, a gap in the time series from 2008.5 to 2010.5 hampers the investigation of rapid SV changes. Nevertheless, the 2007.5 jerk in $D$ is clearly seen, in this case about 6 months later than in $H$ and $Z$. The $H$ and $Z$ components show clear SV changes around 2007.0 similar to HER but with different amplitudes. The rapid SV change in horizontal intensity around 2012.5 might be related with insufficiently constrained ones around 2012.0 at KMH, HER and HBK. The $Z, H$ and $D$ components at TSU show one further potential SA pulse around 2013.5, near the end of the time series.

The comparison between the data series and the models shows that both describe the data reasonably well, but neither the global nor the regional model captures the amplitude of most of the rapid SV changes. The best agreement is seen between the SAREG model and the HER data, where the abrupt SV changes in 2007.5 and 2010.5 in $D$ and all three in the vertical component are described well by the model. The 2007.0 event in $H$ is captured reasonably by the model, while the $2012.5 \mathrm{SV}$ change in $H$ and the 2012.5 change in $D$ are not fit by 
the model. The global CHAOS-5 model seems to do slightly better for these two events, while describing the other rapid SV changes slightly less well. At HBK, the agreement between data and both models is similarly good in $D$ but clearly better for the regional SAREG model in $H$ and $Z$. At both $\mathrm{KMH}$ and TSU, there is reasonable, but variable, agreement between the data and both models, and from the visual comparison, a general statement which of the models fits the data better is not possible. The changes of SV trends shown by the models in these two cases often show temporal offsets compared to the data, e.g. around 2009 in the $H$ and $Z$ components in KMH or around 2007 in $D$ and $Z$ at TSU. In general, global models considering satellite data are superior to regional ground-based models in separating internal and external field contributions. Rapid external field variations should have been eliminated well in the quiet-time monthly mean data, while we detect no systematic differences between the global and regional model which might indicate significant influences from residual large-scale magnetospheric fields in the SAREG model.

\section{Discussion of observed rapid secular variation changes}

The new SAREG regional geomagnetic field model for the southern African region based on observatory and repeat station data from 2005 to 2014 (Figs. 3, 4 and 5) and an investigation of quiet monthly mean time series at the four observatory locations in South Africa and Namibia (Figs. 6, 7, 8 and 9) provide a detailed description of main field and secular variation morphology in that area and estimates of the strength of surface SA pulses at several locations (Table 3). We found that the previously documented 2007 SA pulse (Chulliat et al. 2010; Kotzé 2010; 2011) did not occur simultaneously in all field components and all areas and that the same is even more true for more recent rapid SV variations seen around 2010 (Chulliat and Maus 2014) and 2012 (Chulliat et al. 2015). This behaviour of the non-linear field components, $D=\tan ^{-1}(Y / X)$ and $H=\left(X^{2}+Y^{2}\right)^{1 / 2}$, at the Earth's surface can in fact be expected even from a regional, common source like an SA pulse at the CMB as suggested by Chulliat and Maus (2014). However, the three events show very different morphologies.

Indications of the 2007 event are seen over the whole region and in all components: in $D$ around 2007.5 in the centre of the studied region (e.g. HBK) and slightly later but with somewhat higher amplitudes to the north (e.g. TSU) and south (e.g. HER); in $H$ starting even earlier ( 2007.0) in the south and centre (e.g. HER, HBK) but with clearly lower amplitude than later in the north (e.g. TSU, 2007.7); and in $Z$ rather early ( 2007.0) everywhere, again with the highest amplitude in the north (see, e.g. TSU compared to HBK in Table 3). This jerk is characterized by a change from positive to negative SA in $D$ and from negative to positive SA in $H$ and $\mathrm{Z}$ over the whole area.

The 2011 jerk described by Chulliat and Maus (2014) from northern African and French Guyana data is not clearly described by one rapid change of SV trend in the southern African region. In $D$, the regional model suggests a simultaneous jerk around 2010.5 over the whole area, but the time series investigation reveals that the model apparently does not fully resolve the structure: there is a, probably small, central region where actual change occurs nearly a year later (KMH). In $H$ and $Z$, this event is not characterized by a sudden jump from positive to negative SA, but that change occurs around 1 or 2 years of nearly constant SV in most parts of the studied area. The earliest occurrence ( 2008.5) from positive to nearly constant or slightly negative SA shows in the central eastern region in $Z$ (see HBK) and in large parts is observed around 2009.5 in both $H$ and $Z$. The change from nearly constant to clearly negative SA in those components first occurs in the central parts, around 2010.0 (HBK, KMH) and later in the south (HER).

The time series and regional model maps show rapid SV variations that might be manifestations of the $\mathrm{CMB}$ secular acceleration pulse 2012.5 described by Chulliat et al. (2015) but also additional ones that occur earlier. The surface observations around this time show even more complicated structures than for the other two events. Southern and central parts of the area display rapid SV changes in $H$ and $Z$ as early as 2012.0 (HER, HBK, KMH in $H$, but not in $Z$ ) and, in the west, in $D$ at 2012.5 (HER, KMH) and further north at TSU around 2013.5, while SV remains nearly constant in the latter component at HBK. The 2013.0 and 2013.5 observations are probably related to the suggested 2012.5 SA pulse, recently noted to manifest at the surface in Europe, North Africa and in the Atlantic (Ascension Island) in the eastward field component around 2014.0 and in Guam in 2013.2 by Torta et al. (2015). Signatures at or before 2012.5 at the Earth's surface appear too early to be related to the same source.

In general, we note opposite signs of consecutive SA pulses at the surface, although with quite variable amplitudes and, in particular in the case of the 2011 event, including two-step changes with several months of nearly zero SA in the $H$ and $Z$ components. The alternating signs are in principle consistent with the alternating CMB secular acceleration pulses described by Chulliat et al. (2015), but in particular, our surface observations around 2012 indicate an additional or more complicated source than just a pulse similar to their 2006 one.

Brown et al. (2013) concluded from their investigation of observatory data between 1957 and 2008 that the periodicity in the polarity of geomagnetic jerks regularly 
oscillate between similar minimum and maximum strengths. This investigation of southern African geomagnetic field data between 2005 and 2014, however, showed that this is not the case as we do not observe consecutive SA pulses at any observatory of comparable amplitudes.

\section{Conclusions}

We have presented SAREG, a new regional geomagnetic field model for the $D, H$, and $Z$ components of the geomagnetic field and its secular variation over southern Africa for the time interval 2005.5 to 2014.5. The model will serve as a tool for practical purposes, e.g. to provide declination information for navigational applications. We have cross-validated the regional model with the global CHAOS-5 spherical harmonic model, the first model using satellite data and spanning the 2010-2013 gap between the CHAMP and Swarm satellite missions, where no near-Earth vector field satellite data are available. Moreover, we have used it to investigate the morphology of the very active secular variation in this part of the world and in particular the structure of three recently detected geomagnetic jerks around 2007, 2011 and 2014.

The analysis of fit of the regional and global model to all available southern African ground data indicates a similar performance with the regional model providing slightly smaller root-mean-square misfit. No correction for large-scale, slowly varying magnetospheric fields has been applied to the ground data used for the SAREG model. The comparison among quiet-time observatory data, the global and regional model indicates that such contributions can be neglected here. None of the two models describes the most rapid secular variation changes seen in the data fully in most cases, but both in general provide a good description of southern African secular variation. Differences between the two models vary over time and location, and the CHAOS-5 model does not perform notably worse during the gap in near-Earth satellite vector data.

Our study confirmed once more the often-noted inhomogeneous occurrence of jerks in individual field components and at different locations and their recently noted abundance. Consecutive, alternating SA pulses at the CMB have recently been suggested to cause a 2007, 2011 and 2014 jerk at the Earth's surface. However, in southern Africa, the 2007 jerk appears comparatively more homogeneous than the two later ones, with the 2011 one showing a broad rather than truly rapid SV change with 1 to 2 years of nearly constant SV in the horizontal and vertical components in some areas and a very diverse pattern of surface SA pulses from 2012.0 to 2013.5 (the last resolvable epoch in our study), indicating an additional or more complicated source than for the 2007 event. Future global field models based on
Swarm satellite data including ground observations up to 2015 will cover the recent part of that event better and could bring new insights into the potential complexity of its source.

\section{Competing interests}

The authors declare they have no competing interests.

\section{Authors' contributions}

PK drafted the initial document and made all the plots and tables. MK has been involved in the interpretation of results and critically revising sections for scientific content. Both authors read and approved the final manuscript.

\section{Author details}

${ }^{1}$ South African National Space Agency (SANSA), Space Science, Hermanus, South Africa. ${ }^{2}$ Helmholtz-Zentrum Potsdam, Deutsches GeoForschungsZentrum—GFZ, Potsdam, Germany.

Received: 10 December 2015 Accepted: 28 January 2016

Published online: 17 February 2016

\section{References}

Ardizone J, Herraiz M (2000) Application of the polynomial adjustment to the aeromagnetic survey of the Spanish mainland: requirement and shortcomings. Earth Planets Space 52:183-196

Brown WJ, Mound JE, Livermore PW (2013) Jerks abound: an analysis of geomagnetic observatory data between 1957 and 2008. Phys Earth Planet Inter 223:62-76. doi:10.1016/j.pepi.2013.06.001

Bullard EC (1948) The secular change in the Earth's magnetic field. Monthly Notices Royal Astronomical Society Geophysics Supplement 5:248-257

Cain JC, Daniels WE, Hendricks SJ, Jensen DC (1965) An evaluation of the main geomagnetic field 1940-1962. J Geophys Res 70:3647-3674

Chulliat A, Maus S (2014) Geomagnetic secular acceleration, jerks, and a localized standing wave at the core surface from 2000 to 2010. J Geophys Res 119. doi:10.1002/2013JB010604.

Chulliat A, Thébault E, Hulot G (2010) Core field acceleration pulse as a common cause of the 2003 and 2007 geomagnetic jerks. Geophys Res Lett 37. doi:10.1029/2009GL042019

Chulliat A, Alken P, Maus S (2015) Fast equatorial waves propagating at the top of the Earth's core. Geophys Res Lett. doi:10.1002/2015GL064067.

Dawson E, Newitt LR (1978) An analytical representation of the geomagnetic field in Canada for 1975. Part II: the secular change. Can J Earth Sci 15:237-244

Efroymson MA (1960) Multiple regression analysis. In: Ralston A, Wilf HS (eds) Mathematical methods for digital computers. John Wiley, New York, pp 191-203

Finlay CC, Olsen N, Tøffner-Clausen L (2015) DTU candidate field models for IGRF-12 and the CHAOS-5 geomagnetic field model. Earth Planets Space 67:114. doi:10.1186/s40623-015-0274-3

Geese A, Mandea M, Lesur V, Hayn M (2010) Regional modelling of the southern African geomagnetic field using harmonic splines. Geophys J Int 181:1329-1342

Geese A, Korte M, Kotzé P, Lesur V (2011) Southern African geomagnetic variation from 2005 to 2009. S Afr J Geol 114:515-524

Haines GV (1990) Regional magnetic field modeling: a review. J Geomagn Geoelectr 42:1001-1-18

Korte M. (2015) Long-term external field contributions in geomagnetic repeat station results. Proceedings of the XVII IAGA Workshop on Geomagnetic Observatory Instruments, Data Acquisition and Processing. Journal of Indian Geophysical Union. accepted.

Korte M, Mandea M, Kotzé PB, Nahayo E, Pretorius B (2007) Improved observations at the southern African geomagnetic repeat station network. S Afr J Geol 110:175-186. doi:10.2113/gssajg.110.2-3.175

Korte M, Mandea M, Linthe H-J, Hemshorn A, Kotzé P, Ricaldi E (2009) New geomagnetic field observations in the South Atlantic Anomaly region. Ann Geophys 52:65-81

Kotzé PB (2003) The time-varying geomagnetic field of southern Africa. Earth Planets Space 55:111-116

Kotzé PB (2010) The 2007 geomagnetic jerk as observed at the Hermanus Magnetic Observatory. Physics Comment 2:5-6

Kotzé PB (2011) Signature of the 2007 geomagnetic jerk at the Hermanus Magnetic Observatory, South Africa. S Afr J Geol 114(2):207-210. doi:10.2113/gssajg.114.2.207 
Kotzé PB, Mandea M, Korte M (2007) Modelling the southern African geomagnetic field secular variation using ground survey data for 2005. S Afr J Geol 110:187-193. doi:10.2113/gssajg.110.3.187

Kotzé PB, Cilliers PJ, Sutcliffe PR (2015) The role of SANSA's geomagnetic observation network in space weather: a review. Space Weather 13. doi:10.1002/2015SW001279.

Mandea M, Olsen N (2006) A new approach to directly determine the secular variation from magnetic satellite observations. Geophys Res Lett 33, L15306. doi:10.1029/2006GL026616

Mandea M, Olsen N (2009) Geomagnetic and archeomagnetic jerks: where do we stand? Eos 90:208

Mandea M, M Korte D, Mozzoni D, Kotze P (2007) The magnetic field changing over the southern African continent - a unique behaviour. S Afr J Geol 110:193-202

Mandea M, Holme R, Pais A, Pinheiro K, Jackson A, Verbanac G (2010) Geomagnetic Jerks: Rapid Core Field Variations and Core Dynamics, Space Sci Rev, 155, 147-175. doi:10.1007/s11214-010-9663-x

Nahayo E, Kotzé PB (2012) Polynomial modelling of CHAMP satellite data to investigate rapid secular variation fluctuations over southern Africa during 2003 and 2004. Earth Planets Space 64:595-603

Olsen N, Mandea M (2008). Rapidly changing flows in the Earth's core. Nature Geosciences. doi:10.1038/ngeo203

Pavón-Carrasco FJ, Osete M, Torta JM, De Santis A (2014) A geomagnetic field model for the Holocene based on archaeomagnetic and lava flow data. Earth Planet Sci Lett 388:98-109

Thébault $E$ et al (2015) Evaluation of candidate geomagnetic field models for IGRF-12. Earth Planets Space 67:110. doi:10.1186/s40623-015-0273-4

Torta JM, Pavón-Carrasco FJ, Marsal S, Finlay C (2015) Evidence for a new geomagnetic jerk in 2014. Geophys Res Lett. doi: 10.1002/2015GL065501

Xu Y, Wang Y, An Z (1992) An analysis and the models of the geomagnetic secular variation in China for 1950-1985. Acta Geophys Sin 35:740-747

\section{Submit your manuscript to a SpringerOpen ${ }^{\odot}$ journal and benefit from:}

- Convenient online submission

- Rigorous peer review

- Immediate publication on acceptance

- Open access: articles freely available online

- High visibility within the field

- Retaining the copyright to your article

Submit your next manuscript at $\gg$ springeropen.com 